кого, согласно стандартам Болонского процесса. Наше государство сейчас перед выбором новой образовательной парадигмы, которая призвана устранить несоответствие между запросами общества и уровнем образовательных услуг, заменить задачу всестороннего развития личности задачей максимального развития способностей человека к самореализации и самообразования. В статье показана важность Болонского процесса и доказано, что это очень трудный и длительный процесс, который требует, прежде всего, коррекции психолого-педагогической культуры преподавательского состава высших медицинских учреждений, который готов кардинально перестроить учебный процесс. Актуальность этой проблемы трудно переоценить, поскольку она касается не только образования, его реформирования, но и в целом процесса интеграции нашей страны в Европу.

Ключевые слова: Болонский процесс, психолого-педагогическая культура, медицинское образование.

\title{
PSYCHOLOGICAL-PEDAGOGICAL CULTURE OF THE PROFESSORS' STUFF OF THE HIGHER MEDICAL EDUCATIONAL ESTABLISHMENT IN THE CONTEXT OF THE BOLOGNA PROCESS PRINCIPLES
}

\section{O.M. Panko}

Abstract. Ukrainian society has entered the phase of reformation of higher education, including medical education, according to the standards of Bologna process. Our state faces presently the choice of new educational paradigm which aims at removing disparity between the requirements of the society and the level of educational services, at replacing the aim of comprehensive personality development with the aim of maximal development of person's abilities to self-realization and self-education. The importance of Bologna process is shown in the article; it is proven that it is an extraordinarily difficult and prolonged process, which requires, first of all, the correction of psychological and pedagogic culture of teaching staff of higher medical institutions, which is ready to reconstruct cardinally the educational process. It is difficult to overestimate the urgency of the problem, as it concerns both the education and its reformation, as well as the process of integration of our country into Europe.

Key words: Bologna process, psychological and pedagogic culture, medical education.

National Medical University (Ivano-Frankivsk)

Рецензент - д. псих. н. А.С. Борисюк

Buk. Med. Herald. - 2014. - Vol. 18, № 1 (69). - P.191-194

Надійшла до редакції 27.12.2013 року

\section{(C) O.М. Панько, 2014 \\ УДК 378.016:54:[378.6:61(477.85-25) \\ O.O. Перепелиця \\ МЕТОДИЧНІ ПІДХОДИ ВИКЛАДАННЯ ХІМІЇ НА ПІДГОТОВЧОМУ ВІДДІЛЕННІ ДЛЯ ГРОМАДЯН УКРАЇНИ У БУКОВИНСЫКОМУ ДЕРЖАВНОМУ МЕДИЧНОМУ УНІВЕРСИТЕТІ}

Буковинський державний медичний університет, м. Чернівці

Резюме. У статті розглянуто методичні підходи при викладанні курсу хімії за умов обмеженої кількості годин слухачам із різними навчальними можливостями, що навчаються на підготовчому відділенні для громадян України Буковинського державного медичного університету. За результатами діагностики рівня сформованості розумових дій виділено три групи підлітків - 3 творчим, конструктивним та репродуктивним типом мислення. Пропонується на заняттях, що охоплюють грунтовні, базові теми, використовувати пояснювально-ілюстративне навчання 3 елементами проблемності, а в групах слухачів із творчимконструктивним типом мислення в розділах, що $є$ логічним завершенням базових тем, застосовувати метод випе-

Вступ. Позашкільна освіта є складовою системи безперервної освіти, яка спрямована на задоволення інтересів і потреб абітурієнтів у професійному самовизначенні. Тому завдання, яке ставиться перед викладачами підготовчих курсів, організованих при навчальних закладах, - надання якісних освітніх по(C) О.О. Перепелиця, 2014 реджаючих знань. Систематизацію і структуризацію навчального матеріалу здійснювати шляхом використання графологічних схем та таблиць. Рекомендується опрацювання навичок здійснювати в усіх групах слухачів, незалежно від рівня знань, при цьому, у групах 3 творчимконструктивним типом мислення ще й додатково вирішувати завдання, що $є$ змодельованими реальними ситуаціями та задачі підвищеної складності. Позааудиторну самостійну роботу організовувати з урахуванням різних навчальних можливостей підлітків шляхом розробки диференційованих за рівнем складності завдань.

Ключові слова: слухачі підготовчого відділення, тип мислення, викладання хімії, методичні підходи.

слуг. Ретельна підготовка майбутніх абітурієнтів до вступу у ВНЗ $є$ основною метою й викладачів підготовчого відділення для громадян України Буковинського державного медичного університету.

Викладання хімії на підготовчому відділенні має ряд особливостей. Основна мета навчання на 
підготовчих курсах - систематизація та структуризація знань, одержаних учнями в школі. Програма $3 \mathrm{HO}$ з хімії охоплює 47 тем і розрахована на 108 год занять (з них 54 год - вебінари). Якщо врахувати, що в окремих підлітків, які вступають на підготовче відділення, слід ліквідовувати прогалини у знаннях із більшості тем і те, що в школах на курс хімії з 7-го по 11-й клас виділено всього 245 годин (рівень стандарту) і тільки в спеціалізованих ліцеях i гімназіях - 665 год (профільний рівень), то стає зрозумілим, що часові можливості викладача підготовчого відділення обмежені. Крім того, зваживши, що на підготовче відділення вступають учні з різними навчальними можливостями, виникла потреба розробки нових підходів при викладанні хімії з урахуванням усіх особливостей.

Мета дослідження. Пошук методичних підходів викладання курсу хімії слухачам підготовчого відділення з різними навчальними можливостями за умов обмеженої кількості годин на предмет.

Матеріал і методи. Обрана для моніторингу група охоплює 47 підлітків, які навчаються на підготовчому відділенні Буковинського державного медичного університету в поточному році. У роботі використані методи: спостереження, систематизація, узагальнення, теоретичний та статистичний аналіз.

При розробці методологічних підходів базовими нормативно-правовими документами $є$ закони України «Про освіту», «Про позашкільну освіту», «Концепція загальної середньої освіти» та наукові засади організації навчальновиховного процесу А. Я. Цюприка [8].

Результати дослідження та їх обговорення. Наявність слухачів із різним рівнем шкільної підготовки передбачає диференційований підхід до кожної категорії підлітків, як із підвищеними навчальними можливостями, так і тих, що відчувають труднощі в навчанні. Слухачі з підвищеними навчальними можливостями (творчий рівень сформованості розумових дій) характеризуються довготривалим запам'ятовуванням навчального матеріалу, швидкістю реакції, вмінням піддавати сумніву і науковому осмисленню певні явища, а також володіють навичками самоконтролю в на-

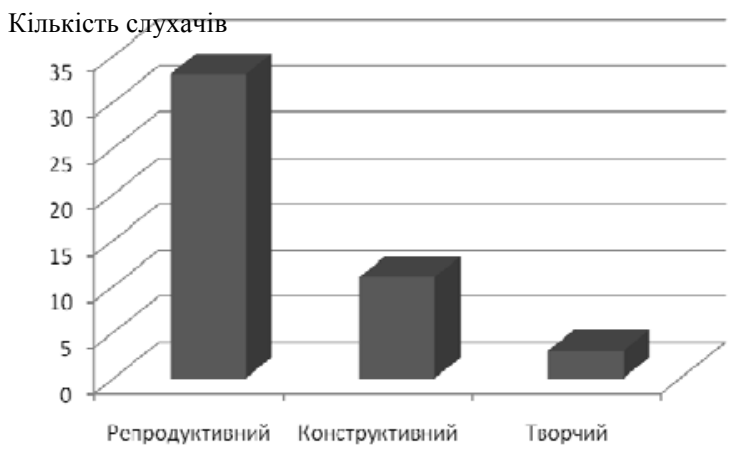

Рис. 1. Розподіл слухачів підготовчого відділення за рівнем сформованості розумових дій вчальній діяльності. А тому і підхід до них використовуємо нестандартний з елементами креативної педагогіки, основою якої $є$ пошукова діяльність - пошук рішення проблемної ситуації $[1,2$, $4,6]$. Разом з тим, ми бачимо проблему - відставання підлітків у навчанні. За даними Ю. К. Бабанського, В. С. Цетліна, М. І. Мурачковського, контингент учнів, які відчувають труднощі в навчанні, становить біля 12,5 \% від всієї кількості осіб [5]. Тому для визначення рівня індивідуальних досягнень слухача на першому занятті з хімії проводиться тестування з розробленими різнорівневими завданнями. Результати дають змогу перевірити як володіє підліток такими прийомами розумової діяльності, як синтез, аналіз, порівняння. Для більшості слухачів (70,2 \%) досліджуваної групи властивий репродуктивний рівень сформованості розумових дій (рис. 1), тобто, підліток може працювати тільки за наявності алгоритмів. Значно менша кількість слухачів (23,4 \%) зареєстрована 3 конструктивним типом мислення, тобто, підліток вміє застосувати знання і навички при аналогії в подібних ситуаціях. Слухачі з дослідницьким (творчим) типом мислення становили всього 6,38 \%.

Така діагностика рівня сформованості розумових дій дає можливість підібрати методичні прийоми роботи з слухачами підготовчого відділення. Поперше, низький вихідний рівень знань більшості підлітків 3 хімії передбачає застосування пояснювально-ілюстративного навчання 3 елементами проблемного навчання. I хоча пояснювально-ілюстративне навчання орієнтоване на репродуктивне засвоєння знань, умінь і навичок, але й забезпечує достатнє засвоєння навчальної інформації в тих випадках, коли зміст навчального матеріалу має переважно інформативний характер, або є дуже складним для того, щоб слухачі здійснювали самостійний пошук знань. Проблемне навчання, що передбачає послідовну і цілеспрямовану постановку пізнавальних завдань перед підлітками, які вони вирішують під керівництвом викладача, потребує великої затрати часу й, на нашу думку, є малоефективним при засвоєнні матеріалу слухачами підготовчого відділення з репродуктивним типом мислення.

По-друге, у зв'язку з обмеженою кількістю годин використовуємо короткий курс викладання

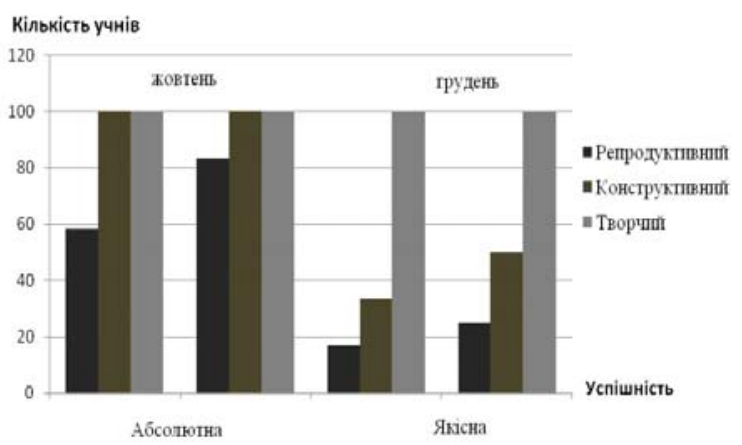

Рис. 2. Моніторинг успішності слухачів підготовчого відділення з різним типом мислення 
iз застосуванням фактичного матеріалу з орієнтацією підлітків на структуровані конспекти, які дозволяють легко систематизувати та узагальнити великий обсяг інформації. Особливістю структурованого конспекту $є$ інформація в зручній i доступній для сприйняття формі - у графологічних схемах і таблицях. Наочність і стислість схематичного викладу матеріалу дозволяє підліткам легше орієнтуватися у складних темах. Така форма подачі теоретичного матеріалу суміщає в собі функції навчального посібника і довідника.

По-третє, у групі підлітків із підвищеними навчальними можливостями в тих розділах, які є логічним довершенням базових тем, використовуємо метод випереджаючих знань, що підвищує пізнавальну діяльність підлітків із творчим рівнем сформованості розумових дій.

По-четверте, перевірку основних понять, законів та теорій теми здійснюємо за допомогою тестового контролю дистанційно в системі «Moodle», а глибше засвоєння понять - не регулярним повторенням теоретичних питань, а використанням завдань, виконання яких потребує знань основних понять теми та уміння їх застосовувати. Такий підхід, на нашу думку, закладають основи не формальних, а фактичних знань. Важливо не поділяти підлітків на групи з метою урізноманітнення форм контролю, а працювати з усією аудиторією над кожною навичкою. А для підлітків із підвищеними навчальними можливостями пропонуємо, крім того, перелік додаткових завдань.

По-п'яте, чітко організовуємо позааудиторну самостійну роботу, яка, за умов обмеженої кількості годин 3 предмета, повинна бути «керованою» й ефективною [7]. Домашні завдання чітко сплановані, з урахуванням індивідуальних особливостей слухачів, їх запитів та інтересів й повідомляються на занятті $з$ коментарем щодо їх виконання. До кожної теми дається графологічна структура, за якою підлітки, які відчувають труднощі в навчанні, вдома виписують основні поняття теми, а слухачі з підвищеними навчальними можливостями готують порівняльний аналіз текстової інформації з різних підручників. Для підлітків із репродуктивним типом мислення пропонуємо виконання тренувальних вправ, аналогічних до тих, що розв'язувалися на занятті, вирішення тестів I рівня складності. Підліткам із конструктивним та творчим типом мислення пропонуються завдання, що $є$ змодельованими реальними ситуаціями, та завдання підвищеної складності. Такий індивідуальний підхід дозволить слухачам із низьким рівнем самостійності хоч i не досягнути рівня знань слухачів 3 підвищеними навчальними можливостями, але принаймні не відчувати себе «відстаючими» і бути дієвим елементом навчального процесу на занятті.

По-шосте, поряд із традиційними методами навчання на підготовчому відділенні для громадян України запроваджені й інтерактивні методи, які як окремо, так і в поєднанні один з одним до- зволяють охопити освітні потреби слухачів м. Чернівці та прилеглих територій. Дистанційна форма навчання, елементи якої використовуються при викладанні хімії слухачам підготовчого відділення, робить навчання якісно іншим, повноцінним та всеохоплюючим. Слухачі мають можливість прослуховувати вебінари, практикувати навички, моделювати необхідні досліди, проходити тестування для з'ясування свого рівня знань із кожної конкретної теми та в цілому 3 предмета.

Для з'ясування результативності запропонованих методичних підходів здійснювався моніторинг результатів роботи зі слухачами підготовчого відділення протягом першої тріади поточного навчального року, який засвідчив зростання успішності підлітків із репродуктивним та конструктивним типом мислення (рис. 2).

Незначне зростання показників якісної успішності у групі слухачів із репродуктивним типом мислення ми пояснюємо суб' єктивними причинами: по-перше, домінанта шкільної освіти, яку тяжко здолати, - завчити і знати, а не розуміти прогнозувати; по-друге, мотиваційним чинником для підлітків із низькими навчальними можливостями є оцінка, а знання того, що всі вони одержать сертифікат після закінчення курсів підготовчого відділення незалежно від рівня своїх досягнень дозволяє їм формально ставитися до навчання; по-третє, групи охоплюють різних за типом мислення підлітків (творчий-конструктивний, конструктивний-репродуктивний), що викликає певні труднощі організаційного характеру для викладача. Групи слухачів із низькими навчальними можливостями повинні містити до восьми осіб.

\section{Висновки}

Отже, при викладанні курсу хімії слухачам підготовчого відділення 3 різними навчальними можливостями за умов обмеженої кількості годин пропонуємо:

1. На заняттях, що охоплюють грунтовні, базові теми, слід використовувати пояснювальноілюстративне навчання з елементами проблемності. У групах слухачів із творчим-конструктивним типом мислення в розділах, що є логічним завершенням базових тем, доцільно застосовувати метод випереджаючих знань.

2. Систематизацію і структуризацію навчального матеріалу необхідно здійснювати шляхом використання графологічних схем та таблиць.

3. Опрацювання навичок слід здійснювати в усіх групах підлітків, незалежно від рівня знань, при цьому, у групах із творчим-конструктивним типом мислення ще й додатково вирішувати завдання, що $є$ змодельованими реальними ситуаціями, та задачі підвищеної складності.

4. Позааудиторну самостійну роботу доцільно організовувати з урахуванням різних навчальних можливостей підлітків шляхом розробки диференційованих за рівнем складності завдань. 
Перспективи подальших досліджень аспекти організації диференційованих форм роботи з підлітками.

\section{Література}

1. Активні форми та методи навчання хімії / Уклад. К.М. Задорожний. - Х.: Вид. група «Основа», 2008. $141 \mathrm{c}$.

2. Башмаков А.И. Креативная педагогика: методология, теория, практика / А.И. Башмаков; под ред. Ю.Г. Круглова. - М.: Ред.-изд. центр «Альфа», 2002. - 240 с.

3. Буринська Н.М. Викладання хімії у 10-11 класах загальноосвітніх навчальних закладів: метод. посіб. для вчителів / Н.М. Буринська, Л.П. Величко. - Київ; Ірпінь: Перун, 2002. -232 с.

4. Герлун Н. Проблемне навчання як засіб формування пізнавальних творчих здібностей учнів / Н. Герлун // Директор школи. - 2006. - № 1. - С. 27-28.
5. Гриньова М.В. Організація навчальної діяльності підлітків з низьким рівнем досягнень при вивченні предметів природничого циклу / М.В. Гриньова, К.Ю. Вовк / Полт. держ. пед. ун-т ім. В. Г. Короленка. - Полтава, 2001. - 120 с.

6. Замурій Г.В. Проблемне навчання як один із засобів розвитку пізнавальних і творчих здібностей учнів / Г.В. Замурій // Хімія. Основа. - 2008. - № 10. - С. 2-4.

7. Руденко Т.М. Засоби активізації самостійної роботи абітурієнтів / Т.М. Руденко // Освіта. Технікуми. Коледжі. -2006. - № 2 (12). - С. 30.

8. Цюприк А.Я. Організація самостійної роботи студентів технічного коледжу у процесі навчання суспільних дисциплін: автореф. дис. на здобуття наук. ст. канд. пед. наук / А.Я. Цюприк. - К., 2005. - 24 с.

\section{МЕТОДИЧЕСКИЕ ПОДХОДЫ ПРЕПОДАВАНИЯ ХИМИИ НА ПОДГОТОВИТЕЛЬНОМ ОТДЕЛЕНИИ ДЛЯ ГРАЖДАН УКРАИНЫ В БУКОВИНСКОМ ГОСУДАРСТВЕННОМ МЕДИЦИНСКОМ УНИВЕРСИТЕТЕ}

\section{о.О. Перепелица}

Резюме. В статье рассмотрены методические подходы преподавания курса химии в условиях ограниченного количества часов слушателям с различными учебными возможностями, обучающихся на подготовительном отделении для граждан Украины в Буковинском государственном медицинском университете. По результатам диагностики уровня сформирования мыслительных действий выделено три группы подростков с творческим, конструктивным и репродуктивным типом мышления. Предлагается на занятиях, охватывающих базовые темы, использовать объяснительно-иллюстративное обучение, а в группах слушателей с творческим-конструктивным типом мышления в разделах, являющихся логическим завершением базовых тем, применять метод опережающих знаний. Систематизацию и структуризацию учебного материала осуществлять путем использования графологических схем и таблиц. Рекомендуется отработку навыков осуществлять во всех группах слушателей, независимо от уровня знаний, при этом, в группах с творческим-конструктивным типом мышления еще дополнительно решать задачи повышенной сложности. Внеаудиторную самостоятельную работу организовывать с учетом различных учебных возможностей слушателей, путем разработки дифференцированных по уровню сложности заданий.

Ключевые слова: слушатели подготовительного отделения, тип мышления, преподавание химии, методические подходы.

\section{METHODICAL APPROACHES TO TEACHING CHEMISTRY FOR THE PREPARATORY DEPARTMENT FOR UKRAINIAN CITIZENS IN BUKOVINIAN STATE MEDICAL UNIVERSITY}

\section{o.O. Perepelytsia}

Abstract. Methodical approaches to teaching chemistry under conditions of limited amount of teaching hours for students with different learning abilities that are studying at the preparatory department for Ukrainian citizens of Bukovinian medical university are considered in this article. Based on the results of mental activity diagnosis for each group of teenagers methodical techniques for working with students were developed. It is proposed to use explanatory, illustrative training with problematic elements while teaching basic, principal topics, and for the sections that are a logical conclusion of basic topics to use the method of proactive knowledge for the groups of students with creative and constructive mindset. Systematization and structuring of studied material should be conducted through usage of graph-logic schemes and tables. It is advisable to practice skills in all groups of students regardless of their level of knowledge wherein for the groups with creative and constructive mindset tasks modeled from real situations and problems of increased complexity should be solved. Extracurricular independent work should be organized with different learning abilities of students taken in mind by developing tasks that are differentiated by their difficulty rate.

Key words: students, mindset, teaching chemistry, methodical approaches.

Bukovinian State Medical University (Chernivtsi) 